\title{
The Necessity for a Sustainable Traffic Light System: The Case Study of el-Koura District Traffic Light System
}

\author{
Najib Georges ${ }^{1}$, Samer Fawaz \\ ${ }^{1}$ Professor and Chairman of the Civil \& Environmental Engineering Department at the University of Balamand \\ Lebanon \\ najib.georges@balamand.edu.lb \\ ${ }^{2}$ Lecturer in the Civil \& Environmental Engineering Department at the University of Balamand \\ Lebanon \\ samer_fawaz@hotmail.com
}

\begin{abstract}
Traffic congestion is one of the major problems that Lebanon agonizes from. In this case study, the main objective is to provide a smart traffic light system that can reduce congestion in addition to all of its negative effects. The method used for design was the Webster Method. The results are very favorable. The system was optimized to reduce traffic light stops and idle running times provided that the drivers abide by the speed limit on the roadway and try to maintain a constant speed.
\end{abstract}

Keywords: Traffic, Congestion, Traffic Light System, Webster Method.

\section{Introduction}

Traffic congestion is a growing problem in many metropolitan areas. Congestion increases travel time, air pollution, carbon dioxide $\left(\mathrm{CO}_{2}\right)$ emissions and fuel use because cars cannot run efficiently. The number of hours that drivers waste sitting in traffic is tremendous. Some people point to the growth of traffic congestion as evidence of the need for more infrastructure spending; however, there are ways to manage traffic, particularly at times of peak demand that are relatively inexpensive.

In case study, the emphasis would be on exploring smart traffic light system. The traffic lights selected are located on the main arterial roadway starting in the town of Kfarhazir and ending in the town of Kousba, crossing the capital of the elKoura District, Amioun, and running through the towns of Kfarsaroun, and Kfaraaqa. Figure 1 provides an overview of the roadway. The selected roadway is a major roadway and very vital to the District (Caza) of el-Koura in North Lebanon. The roadway can be classified as a four-lane two-way urban arterial on a rolling terrain. Traffic congestion on the roadway has major impacts on the economy, environment, and overall life aspects of the surrounding areas.

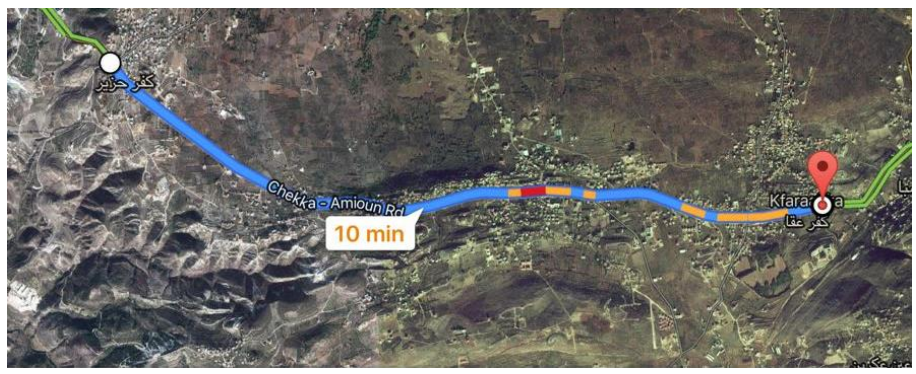

Fig. 1: Bird Eye View of the Roadway.

The proposed system was designed to minimize the time spent at the intersections. The design was realized to ensure a free flow of traffic all through the roadway. The timing of the traffic lights on the intersections were designed in such a way that once the driver passes a green light at a specific intersection at a constant speed of $50 \mathrm{~km} / \mathrm{h}$, he/she will proceed to find all other traffic lights to be green, provided that he/she maintains a constant speed. If the driver tends to decrease or 
increase the speed, he/she probably might have to stop at the next intersection. This type of traffic light system design can definitely assist to ensure a constant free flow of traffic all through the roadway, at all intersections.

\section{Base Line Survey of the Traffic Conditions and Their Effects}

Lebanon is a country that is very lagging when it comes to transport, and especially transport management systems. The lack of data collection, in addition to the chaos and negligence that dominates over the sector from the government's side, has led to a much deteriorated condition of the transport sector.

The fact that no national code for roadway and infrastructure design exists, added to mal-practices in the design of all facilities related to the transport sector, in addition to wrong signalization of roadways and intersections, has led to the current traffic situation that Lebanon suffers from. All this is compounded by the mere fact of the exponential increase in the number of vehicles without any growth in the capacity of the roadways.

The lack of awareness and understanding of traffic rules is a common problem in Lebanon. Accidents do happen on a regular basis. These accidents result in a very high fatality and injury rate, in addition to materialistic losses, in terms of working days and hospitalization. Losses due to accidents are estimated to be around $1.5 \%$ of the GDP [1]; not to mention that these accidents might result in families losing their main provider(s).

The town of Amioun suffers from traffic jam during rush hours and addition to the fact that a considerable number of drivers do not respect the posted speed limit.

Moreover, traffic congestion is another problem that the region suffers from. The density of passenger vehicles on the roads, in addition to the lack of signalization and infrastructure, has led to a major problem that affects all the lives of the inhabitants. Traffic congestion is estimated to cost Lebanon around 10\% of the GDP [1]. The financial losses due to running vehicles stuck in traffic and loss of working hours of the Lebanese work force while waiting in traffic congestions is tremendous [2].

Additionally, the traffic congestion and bad design of the timing of the traffic lights have led to excessive emissions due to burning fuel of idle running vehicles. The air pollution resulting from the transport sector in Lebanon constitutes one of the largest sources of emissions in the country [3].

\section{Proposed Solution for the Amioun - Kousba Highway}

Since one of the major problems of the investigated roadway is the three major intersections that have been poorly designed, thus resulting in major congestion on the roadway in general and specifically at the intersections, a smart traffic light timing system has been adopted for this case study as a solution. The three traffic lights were designed to provide a continuous flow of traffic.

The cycle length and the timings of the traffic lights were designed so as once the first traffic light turns green, the driver should proceed to the next traffic light only to find it green, where he/she can proceed to the next and so on, provided that the driver maintains a constant speed of $50 \mathrm{~km} / \mathrm{h}$; therefore, the idle running time of the vehicles is reduced to a minimum.

Since the discussed traffic light design reduces vehicles stops and delays, all the negative effects cited above are reduced. This specific design forces the drivers to drive at a constant speed of $50 \mathrm{~km} / \mathrm{h}$, excess speed is reduced, which reduces the accident rates. Additionally, the pollution produced by the vehicles is immensely reduced, since the idle running time is reduced. The financial losses are reduced too, and the time spent to reach the destinations is reduced.

\section{Adopted Methodology}

Two of the most common methods usually used to calculate the cycle length, the Webster Method and the Highway Capacity Method (HCM) [4]. The Webster Method may be applied to situations unlike the HCM. The HCM is a method that calculates the cycle length based on the highest flow, depending on the effective green time of a certain lane group; however, it was found that when designing the traffic lights for this region, the HCM method may not be applicable. The reason being that using the HCM requires a saturation flow of 1,900 vehicle/hour/lane; however, such a saturation flow cannot be applied to Lebanon, the reason being that the specific variable " $h$ " that is described to be the "time headway" is significantly reduced; the time headway is the interval time between vehicles that are driving in the same direction. Due to Lebanon's reckless driving the space headway is significantly reduced; therefore, the saturation flow is much higher than 
1900 vehicle/hour/lane. As soon as the lights turn green, all the vehicles move at once, not respecting the safe distances between one another.

The saturation flow is given by:

$$
S=\frac{3600}{h}
$$

where $\mathrm{S}$ is the saturation flow [5].

Having very small time headway may cause the saturation flow to be much higher than 1900 vehicle/hour/lane. Lebanon has no study regarding traffic flow patterns and transportation. The best that can be done is an approximation to a country with a similar traffic behavior. After conducting a thorough investigation, it was found that Saudi Arabia had a saturation flow rate of 2500 vehicle/hour/lane. This number seems logical for Lebanon since Lebanese drivers have a similar behavior regarding space headway and traffic light flow.

\section{Flow Number Calculation Using the Webster Method 5.1. Average Annual Daily Traffic (Aadt) \\ 5.1.1. Initial Car Count}

Several hours were sampled in order to estimate the traffic flow at the three intersections. Vehicles were monitored at each of the three intersections. Then after collecting traffic counts of certain hours on different days, expansion factors were used to estimate the average daily traffic. Since Lebanon lacks in terms of traffic studies and development of factors, factors from the NRA of Dublin were adopted due to many similarities between Lebanon and Dublin in terms of traffic flow behavior. Note that the East and West directions have two lanes in each direction, while the North and South directions have one lane in each direction.

\subsubsection{Hourly Traffic Flow (HTF)}

After the vehicle count was finalized, Table 1 is used to convert the numbers based on the hours of counts.

Table 1: Hourly Traffic Flow as Proportion of 24-Hour Traffic Flow.

\begin{tabular}{|c|c|c|c|c|c|c|}
\hline \hline Hour Ending & $1: 00$ & $2: 00$ & $3: 00$ & $4: 00$ & $5: 00$ & $6: 00$ \\
\hline \hline Greater Dublin area & 0.008 & 0.005 & 0.003 & 0.004 & 0.006 & 0.017 \\
\hline Major inter Urban (Excl. GDA) & 0.009 & 0.005 & 0.004 & 0.004 & 0.006 & 0.013 \\
\hline West and South west & 0.007 & 0.004 & 0.002 & 0.002 & 0.003 & 0.003 \\
\hline All other areas & 0.007 & 0.004 & 0.003 & 0.003 & 0.004 & 0.011 \\
\hline \hline Hour Ending & $\mathbf{7 : 0 0}$ & $\mathbf{8 : 0 0}$ & $\mathbf{9 : 0 0}$ & $\mathbf{1 0 : 0 0}$ & $\mathbf{1 1 : 0 0}$ & $\mathbf{1 2 : 0 0}$ \\
\hline \hline Greater Dublin area & 0.049 & 0.072 & 0.073 & 0.059 & 0.053 & 0.054 \\
\hline Major Inter Urban (Excl. GDA) & 0.030 & 0.064 & 0.077 & 0.062 & 0.055 & 0.057 \\
\hline West and South west & 0.021 & 0.062 & 0.073 & 0.060 & 0.056 & 0.059 \\
\hline All other areas & 0.026 & 0.060 & 0.070 & 0.061 & 0.056 & 0.059 \\
\hline \hline Hour Ending & $\mathbf{1 3 : 0 0}$ & $\mathbf{1 4 : 0 0}$ & $\mathbf{1 5 : 0 0}$ & $\mathbf{1 6 : 0 0}$ & $\mathbf{1 7 : 0 0}$ & $\mathbf{1 8 : 0 0}$ \\
\hline \hline Greater Dublin area & 0.056 & 0.058 & 0.061 & 0.068 & 0.079 & 0.085 \\
\hline Major Inter Urban (Excl. GDA) & 0.060 & 0.063 & 0.065 & 0.071 & 0.082 & 0.090 \\
\hline West and South west & 0.062 & 0.063 & 0.065 & 0.071 & 0.081 & 0.089 \\
\hline All other areas & 0.064 & 0.067 & 0.070 & 0.075 & 0.084 & 0.090 \\
\hline Hour Ending & $\mathbf{1 9 : 0 0}$ & $\mathbf{2 0 : 0 0}$ & $\mathbf{2 1 : 0 0}$ & $\mathbf{2 2 : 0 0}$ & $\mathbf{2 3 : 0 0}$ & $\mathbf{2 4 : 0 0}$ \\
\hline \hline Greater Dublin area & 0.074 & 0.056 & 0.041 & 0.032 & 0.023 & 0.014 \\
\hline Major Inter Urban (Excl. GDA) & 0.074 & 0.054 & 0.041 & 0.031 & 0.022 & 0.014 \\
\hline West and South west & 0.075 & 0.054 & 0.039 & 0.030 & 0.021 & 0.013 \\
\hline All other areas & 0.073 & 0.055 & 0.041 & 0.031 & 0.021 & 0.012 \\
\hline
\end{tabular}




\subsubsection{Average Annual Daily Traffic (AADT) Calculation}

The HTF is then adjusted using Table 2 in order to obtain the Daily Flow Indices (DFI). Next, the AADT is calculated by multiplying the DFI by the Monthly Flow Indices (MFI) from Table 3 depending on the month.

Table 2: Daily Flow Indices.

\begin{tabular}{|c|c|c|c|c|c|c|c|}
\hline Day & Mon & Tue & Wed & Thu & Fri & Sat & Sun \\
\hline $\begin{array}{c}\text { Proportion of } \\
\text { WADT }\end{array}$ & 0.99 & 1.02 & 1.03 & 1.07 & 1.15 & 0.91 & 0.86 \\
\hline Index & 1.01 & 0.98 & 0.97 & 0.93 & 0.87 & 1.10 & 1.16 \\
\hline
\end{tabular}

Table 3: Monthly Flow Indices.

\begin{tabular}{|c|c|c|c|c|c|c|}
\hline Month & Jan & Feb & Mar & Apr & May & Jun \\
\hline $\begin{array}{c}\text { Proportion of } \\
\text { AADT }\end{array}$ & 0.94 & 0.94 & 0.96 & 1.02 & 1.03 & 1.04 \\
\hline Index & 1.06 & 1.06 & 1.04 & 0.98 & 0.97 & 0.96 \\
\hline Month & Jul & Aug & Sep & Oct & Nov & Dec \\
\hline $\begin{array}{c}\text { Proportion of } \\
\text { AADT }\end{array}$ & 1.06 & 1.06 & 1.04 & 1.01 & 0.96 & 0.96 \\
\hline Index & 0.94 & 0.93 & 0.96 & 0.99 & 1.04 & 1.04 \\
\hline
\end{tabular}

\subsection{Flow Numbers}

\subsubsection{Calculating Design Hourly Volume (DHV)}

The DHV is calculated as 8 to 12 percent of the AADT. In urban regions, it is preferred that the maximum percent be taken. Therefore, AADT is multiplied by 0.12 in order to obtain the DHV.

\subsubsection{Calculating DHV (including Trucks)}

While counting vehicles along the Amioun main road, it was noted that approximately $7 \%$ of the total vehicles were trucks. Following the rules of the Webster method, 1 truck is considered equivalent to 1.6 passenger cars.

Therefore, to obtain the total DHV, apply the following formula:

Total DHV $=\mathrm{DHV}+0.07 \times \mathrm{DHV} \times 1.6$

\subsubsection{Calculating Equivalent Straight-Through Passenger Cars (ESTP)}

The ESTP for the lanes that do not include left turns are equal to the Total DHV. As for all lanes that include left turns, the DHV for the left turning vehicles is multiplied by 1.4 .

\subsubsection{Flow Numbers}

For each lane, the Flow Number $=$ Sum of the ESTP for all directions, as shown in Tables 4, 5, and 6. 
Table 4: Intersection 1 Flow Number Calculations.

\begin{tabular}{|c|c|c|c|c|c|c|}
\hline & NS & NW & NE & SN & SE & SW \\
\hline $\begin{array}{c}\text { Intersection } \\
\mathbf{1}\end{array}$ & 5 & 6 & 7 & 246 & 94 & 37 \\
\hline HTF & 39.1 & 46.9 & 54.7 & 1921.9 & 734.4 & 289.1 \\
\hline WEF & 38.7 & 46.4 & 54.1 & 1902.8 & 727.1 & 286.2 \\
\hline AADT & 40.3 & 48.3 & 56.4 & 1982.1 & 757.4 & 298.1 \\
\hline DHV & 4.8 & 5.8 & 6.8 & 237.9 & 90.9 & 35.8 \\
\hline $\begin{array}{c}\text { DHV (7\% } \\
\text { trucks x 1.6) }\end{array}$ & 6 & 7 & 8 & 265 & 102 & 39.8 \\
\hline ESTP & 6 & 7 & 12 & 265 & 102 & 56 \\
\hline Flow \# & \multicolumn{7}{|c|}{250} & WS & WN & EW & EN & ES \\
\hline & WE & WS & 144 & 771 & 2 & 202 \\
\hline $\begin{array}{c}\text { Intersection } \\
\mathbf{1}\end{array}$ & 19 & 625 & \multicolumn{2}{|c|}{} & \\
\hline HTF & 148.4 & 4882.8 & 1125 & 6023.4 & 15.6 & 1578.1 \\
\hline WEF & 147 & 4834.5 & 1114 & 5963.8 & 15.5 & 1562.5 \\
\hline AADT & 153.1 & 5036 & 1160 & 6212.3 & 16.1 & 1627.6 \\
\hline DHV & 18.4 & 604.3 & 139 & 745.5 & 1.9 & 195.3 \\
\hline $\begin{array}{c}\text { DHV (7\% } \\
\text { trucks x 1.6) }\end{array}$ & 21.0 & 672.0 & 155 & 829 & 3 & 217.2 \\
\hline ESTP & 21.0 & 672.0 & 217 & 829 & 3 & 305 \\
\hline Flow \# & \multicolumn{2}{|c|}{693} & 217 & \multicolumn{2}{|c|}{832} & \\
\hline
\end{tabular}

16692.5

AADT

17388

\section{DHV} 2086.6

Table 5: Intersection 2 Flow Number Calculations.

\begin{tabular}{|c|c|c|c|c|c|c|}
\hline & NS & NW & NE & SN & SE & SW \\
\hline $\begin{array}{c}\text { Intersection } \\
\mathbf{2}(+\mathbf{4} \text { km) }\end{array}$ & 59 & 268 & 271 & 19 & 72 & 89 \\
\hline HTF & 460.9 & 2093.8 & 2117 & 148.4 & 562.5 & 695.3 \\
\hline WEF & 456.4 & 2073 & 2096 & 147 & 557 & 688.4 \\
\hline AADT & 475.4 & 2159 & 2183 & 153.1 & 580.1 & 717.1 \\
\hline DHV & 57 & 259.1 & 262 & 18.4 & 69.6 & 86.1 \\
\hline $\begin{array}{c}\text { DHV (7\% } \\
\text { trucks x 1.6) }\end{array}$ & 64 & 289 & 292 & 21 & 78 & 96 \\
\hline ESTP & 64 & 289 & 409 & 21 & 78 & 135 \\
\hline Flow \# & \multicolumn{7}{|c|}{762} & & \multicolumn{3}{|c|}{234} & \\
\hline & WE & WS & WN & EW & EN & ES \\
\hline $\begin{array}{c}\text { Intersection } \\
\mathbf{2}(+\mathbf{4 . 3} \text { km) }\end{array}$ & 184 & 815 & 8 & 809 & 184 & 46 \\
\hline HTF & 1437 & 6367.2 & 62.5 & 6320.3 & 1437 & 359.4 \\
\hline WEF & 1423 & 6304 & 61.9 & 6257.7 & 1423 & 355.8 \\
\hline AADT & 1482 & 6567 & 64.5 & 6518 & 1482 & 370.6 \\
\hline DHV & 178 & 788 & 7.7 & 782.2 & 177.9 & 44.5 \\
\hline $\begin{array}{c}\text { DHV (7\% } \\
\text { trucks x 1.6) }\end{array}$ & 198 & 877 & 9 & 870 & 198 & 70 \\
\hline ESTP & 198 & 877 & 13 & 870 & 198 & 70 \\
\hline Flow \# & 1075 & 13 & \multicolumn{2}{|c|}{1068} & 70 \\
\hline
\end{tabular}




\begin{tabular}{|c|c|c|c|c|c|c|c|}
\cline { 2 - 7 } \multicolumn{1}{c|}{} & INT. 2 & HTF & WEF & AADT & DHV & DHV (7\%) & ESTP \\
\hline TOTAL & 2824 & 22062.5 & 21844.1 & 22754.2 & 2730.5 & 3036.3 & 3222 \\
\hline
\end{tabular}

Table 6: Intersection 3 Flow Number Calculations.

\begin{tabular}{|c|c|c|c|c|c|c|}
\hline & NS & NW & NE & SN & SE & SW \\
\hline $\begin{array}{l}\text { Intersection } \\
3(+2.1 \text { km) }\end{array}$ & 184 & 130 & 131 & 81 & 113 & 74 \\
\hline HTF & 1437.5 & 1015.6 & 1023 & 632.8 & 882.8 & 578.1 \\
\hline WEF & 1482 & 1047 & 1055 & 652.4 & 910.1 & 596 \\
\hline AADT & 1543.7 & 1090.7 & 1099 & 679.6 & 948 & 620.8 \\
\hline DHV & 185.2 & 130.9 & 132 & 81.5 & 113.8 & 74.5 \\
\hline $\begin{array}{l}\text { DHV (7\% } \\
\text { trucks x } 1.6)\end{array}$ & 206 & 146 & 147 & 91 & 127 & 83 \\
\hline ESTP & 206 & 146 & 206 & 91 & 127 & 117 \\
\hline Flow \# & & 558 & & & 335 & \\
\hline & WE & WS & $\mathbf{W N}$ & EW & EN & ES \\
\hline $\begin{array}{l}\text { Intersection } \\
3(+2.1 \text { km) }\end{array}$ & 107 & 1004 & 97 & 131 & 130 & 184 \\
\hline HTF & 835.9 & 7843.8 & 758 & 1023.4 & 1015 & 1437 \\
\hline WEF & 861.8 & 8086.3 & 781 & 1055.1 & 1047 & 1482 \\
\hline AADT & 897.7 & 8423.3 & 813 & 1099.1 & 1090 & 1543 \\
\hline DHV & 107.7 & 1010.8 & 97.7 & 131.9 & 130.9 & 185.2 \\
\hline $\begin{array}{l}\text { DHV (7\% } \\
\text { trucks x 1.6) }\end{array}$ & 120 & 1125 & 109 & 147 & 146 & 206 \\
\hline ESTP & 120 & 1125 & 153 & 147 & 146 & 289 \\
\hline Flow \# & \multicolumn{2}{|c|}{1245} & 153 & \multicolumn{2}{|c|}{293} & 289 \\
\hline
\end{tabular}

\begin{tabular}{|c|c|c|c|c|c|c|c|}
\cline { 2 - 7 } \multicolumn{1}{c|}{} & INT. 3 & HTF & WEF & AADT & DHV & DHV (7\%) & ESTP \\
\hline TOTAL & 2366 & 18484.4 & 19056.1 & 19850.1 & 2382 & 2648.8 & 2873 \\
\hline
\end{tabular}

\section{Configuring Traffic Lights}

\subsection{Calculating Saturation Flow Rate}

The saturation flow rate calculations were performed according to the various configurations as shown in Figure 2 $[4,6]$. The adjustment factors used for computing the saturation flow rate are obtained from Table 7 . Note: If the road consists of one lane, all directions are combined in one saturation flow. If it consists of several lanes, the saturation flow for each lane is computed:

$$
s=s_{o} \times N \times f_{w} \times f_{H V} \times f_{g} \times f_{p} \times f_{b b} \times f_{a} \times f_{L U} \times f_{L T} \times f_{R T} \times f_{L p b} \times f_{R p b}
$$

$s=$ saturation flow rate for the subject lane group expressed as a total for all lanes in the lane group (veh/h), taken as 2500

[7].

$f_{p}=$ adjustment factor for the existence of a parking lane and parking activity adjacent to the lane group

$f_{b b}=$ adjustment factor for the blocking effect of local buses that stop within the intersection area

$\mathrm{f}_{\mathrm{Rpb}}=$ pedestrian $>$ bicycle adjustment factor for right-turn movements

$\mathrm{f}_{\mathrm{Lpb}}=$ pedestrian adjustment factor for left-turn movements

$\mathrm{f}_{\mathrm{RT}}=$ adjustment factor for right turns in the lane group

$\mathrm{f}_{\mathrm{LT}}=$ adjustment factor for left turns in the lane group

$\mathrm{f}_{\mathrm{LU}}=$ adjustment factor for lane utilization

$\mathrm{f}_{\mathrm{a}}=$ adjustment factor for area type

$f_{g}=$ adjustment factor for approach grade 
$\mathrm{f}_{\mathrm{HV}}=$ adjustment factor for heavy vehicles in the traffic stream

$\mathrm{f}_{w}=$ adjustment factor for lane width

$\mathrm{N}=$ number of lanes in the group

$\mathrm{s}_{\mathrm{o}}=$ base saturation flow rate per lane $\mathrm{pc} / \mathrm{hr} / \mathrm{lane}$

Table 7: Adjustment Factors for Saturation Flow Rates [4].

\begin{tabular}{|c|c|c|c|}
\hline Factor & Formula & Definition of Variables & Notes \\
\hline Lane width & $f_{w}=1+\frac{(W-12)}{30}$ & $W=$ lane width $(\mathrm{ft})$ & $\begin{array}{l}W \geq 8.0 \\
\text { If } W>16, \text { two-lane } \\
\text { analysis may be } \\
\text { considered }\end{array}$ \\
\hline $\begin{array}{l}\text { Heavy } \\
\text { vehicles }\end{array}$ & $f_{H V}=\frac{100}{100+\% H V\left(E_{T}-1\right)}$ & $\begin{aligned} \% H V= & \text { percent heavy vehicles for lane } \\
& \text { group volume }\end{aligned}$ & $E_{T}=2.0 \mathrm{pc} / \mathrm{HV}$ \\
\hline Grade & $f_{R}=1-\frac{\% G}{200}$ & $\begin{array}{c}\% G=\text { percent grade on a lane group } \\
\text { approach }\end{array}$ & $\begin{array}{l}-6 \leq \% G \leq+10 \\
\text { Negative is downhill }\end{array}$ \\
\hline Parking & $f_{p}=\frac{N-0.1-\frac{18 N_{m}}{3600}}{N}$ & $\begin{aligned} N & =\text { number of lanes in lane group } \\
N_{m} & =\text { number of parking maneuvers } / \mathrm{h}\end{aligned}$ & $\begin{aligned} & 0 \leq N_{m} \leq 180 \\
& f_{p}=\geq 0.050 \\
& f_{p}= 1.000 \text { for no } \\
& \text { parking }\end{aligned}$ \\
\hline Bus blockage & $f_{b b}=\frac{N-\frac{14.4 N_{b}}{3600}}{N}$ & $\begin{aligned} N & =\text { number of lanes in lane group } \\
N_{B} & =\text { number of buses stopping } / \mathrm{h}\end{aligned}$ & $\begin{array}{l}0 \leq N_{B} \leq 250 \\
f_{b b}=\geq 0.050\end{array}$ \\
\hline Type of area & $\begin{array}{l}f_{a}=0.900 \text { in CBD } \\
f_{a}=1000 \text { in all other areas }\end{array}$ & & \\
\hline $\begin{array}{l}\text { Lane } \\
\text { utilization }\end{array}$ & $f_{L U}=v_{g} /\left(v_{g 1} N\right)$ & $\begin{array}{c}v_{g}=\text { unadjusted demand flow rate for } \\
\text { the lane group, veh } / \mathrm{h} \\
v_{g 1}=\text { unadjusted demand flow rate on } \\
\text { the single lane in the lane group } \\
\text { with the highest volume } \\
N=\text { number of lanes in the lane group }\end{array}$ & \\
\hline Left turns & $\begin{array}{l}\text { Protected phasing: } \\
\text { Exclusive lane: } \\
\qquad F_{L T}=0.95 \\
\text { Shared lane: } \\
\quad f_{L T}=\frac{1}{1.0+0.05 P_{L T}}\end{array}$ & $P_{L T}=$ proportion of LTs in lane group & $\begin{array}{l}\text { See pages } 474 \text { through } \\
483 \text { for non- } \\
\text { protected phasing } \\
\text { alternatives }\end{array}$ \\
\hline Right turns & $\begin{array}{l}\text { Exclusive lane: } \\
\quad f_{R T}=0.85 \\
\text { Shared lane: } \\
\quad f_{R T}=1.0-(0.15) P_{R T} \\
\text { Single lane: } \\
\quad f_{R T}=1.0-(0.135) P_{R T}\end{array}$ & $P_{R T}=$ proportion of RTs in lane group & $f_{R T}=\geq 0.050$ \\
\hline $\begin{array}{l}\text { Pedestrian- } \\
\text { bicycle } \\
\text { blockage }\end{array}$ & $\begin{aligned} & \text { LT adjustment: } \\
& f_{L, p b}= 1.0-P_{L T}\left(1-A_{p b T}\right) \\
&\left(1-P_{L T A}\right) \\
& \text { RT adjustment: } \\
& f_{k p b}= 1.0-P_{K T}\left(1-A_{p b T}\right) \\
&\left(1-P_{R T A}\right)\end{aligned}$ & $\begin{aligned} P_{L T}= & \text { proportion of LTs in lane group } \\
A_{p b T}= & \text { permitted phase adjustment } \\
P_{L T A}= & \text { proportion of LT protected green } \\
& \text { over total RT green } \\
P_{R T}= & \text { proportion of RTs in lane group } \\
P_{K T A}= & \text { proportion of RT protected green } \\
& \text { over total RT green }\end{aligned}$ & $\begin{array}{l}\text { See pages } 485 \text { to } 490 \\
\text { for step-by-step } \\
\text { procedure }\end{array}$ \\
\hline
\end{tabular}




\subsection{Calculating Traffic Light Time}

\subsubsection{Amber Light Duration}

The amber light duration is calculated for each of the lanes (as performed for saturation). It includes several variables:

$$
\tau=\frac{W+20}{U 0 \times 1.47}+\frac{U 0 \times 1.47}{2 \times(a+\delta \times 32.2)}
$$

Round-up value to nearest 0.5 .

\subsubsection{Ratios of Approach}

The formula used is simply

$$
Y=\frac{q}{S}
$$

\subsubsection{Optimum Cycle Length $\left(\mathrm{C}_{0}\right)$}

The procedure to calculate the optimum cycle length is as follows [8]:

a. Take max Y from east and west, and take the max between North and South (due to low density)

b.Divide each $\mathrm{Y}_{\max }$ by the sum of all the $\mathrm{Y}_{\max }$

c. $\mathrm{C}_{0}=\left(1.5 \times\right.$ sum of $\left.l_{i}+5\right) /\left(1-\right.$ sum of $\left.Y_{\max }\right), l_{i}$ is the lost time per phase, normally equal to $3.5 \mathrm{~s}$

d. Round $\mathrm{C}_{0}$ up to nearest integer

\subsubsection{Actual Green Light Duration $\left(\mathrm{G}_{\mathrm{ai}}\right)$}

Procedure is as follows [10]:

a. $\mathrm{G}_{\mathrm{te}}=$ Rounded $\mathrm{C}_{0}-\mathrm{L}$

b. $\mathrm{G}_{\mathrm{ei}}=\mathrm{G}_{\mathrm{te}} \times\left(\mathrm{Y}_{\mathrm{i}} /\left(\right.\right.$ sum of $\left.\mathrm{Y}_{\mathrm{i}}\right)$

c. $G_{a i}=G_{e i}+l_{i}-\tau$ (rounded)

\subsubsection{Additional Notes}

The red light duration is the remainder of the cycle time $\mathrm{C}_{0}$.

Also the cycle at the next intersection begins after time $=$ distance $/ \mathrm{U}_{0}$.

\subsection{Configurations Analyzed}

The following configurations were chosen due to the vehicles count. The East and West directions are very dense in terms of vehicles per hour, while the North and South directions are relatively low.

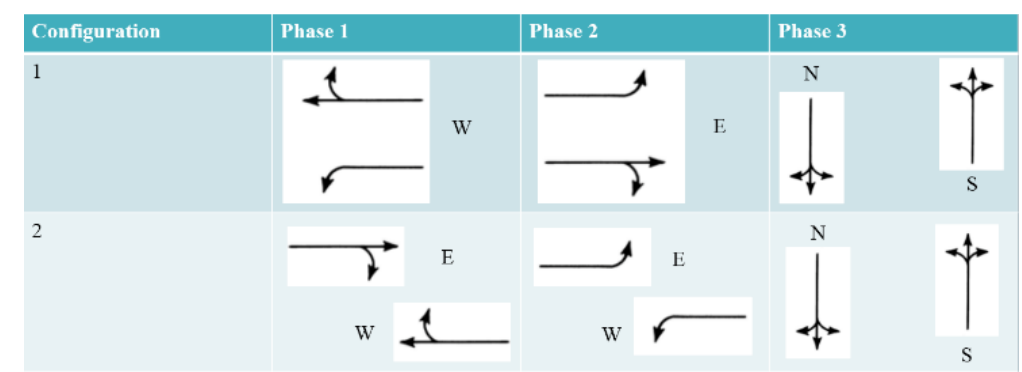

Fig. 2: Different Configurations Considered.

Configuration 1 includes:

Phase 1: All western lanes (lanes coming from West) move together

Phase 2: All eastern lanes move together

Phase 3: All northern and southern lanes move together (and so it repeats)

Configuration 2 includes: 
Phase 1: Eastern and western lanes move together, only the straight and right traffic Phase 2: The left directions of the eastern and western lanes move together Phase 3: All northern and southern lanes move together (and so it repeats)

\section{Final Representation of Design}

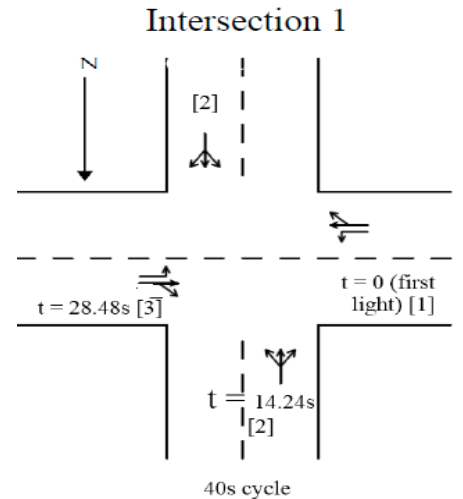

Fig. 3: Timings of Intersection 1.

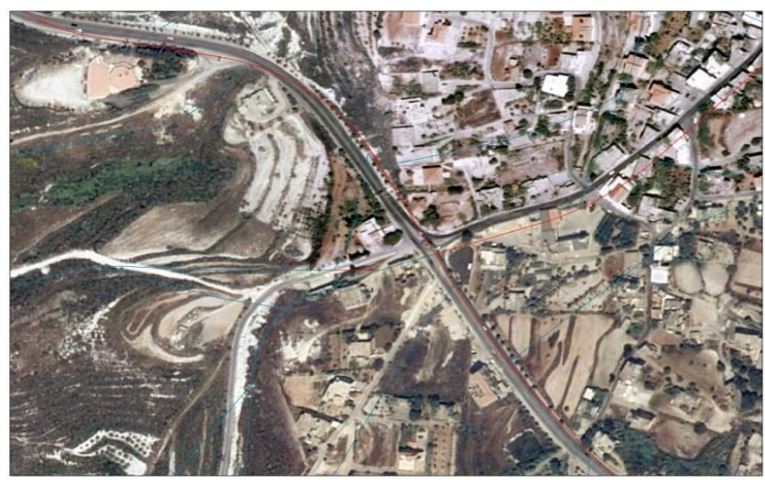

Fig. 4: Plan View of Intersection1.

\section{Intersection 2}

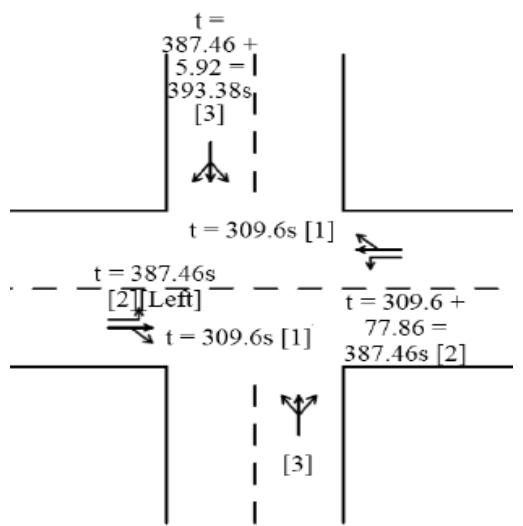

170 s cycle

$309.6 / 40=7.74$

$7.74-7=0.74$

$0.74 * 40=29.6 \mathrm{~s}$

1.12 s delay moving

Fig. 5: Timings of Intersection 2. 


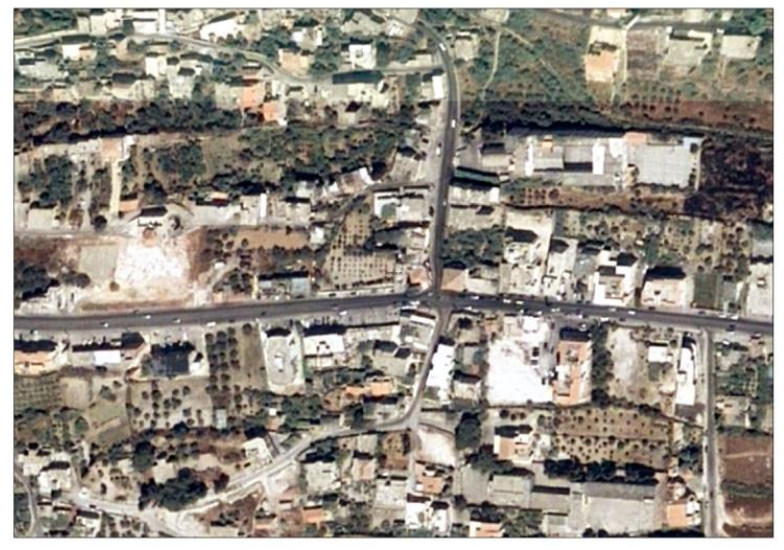

Fig. 6: Plan view of Intersection2.

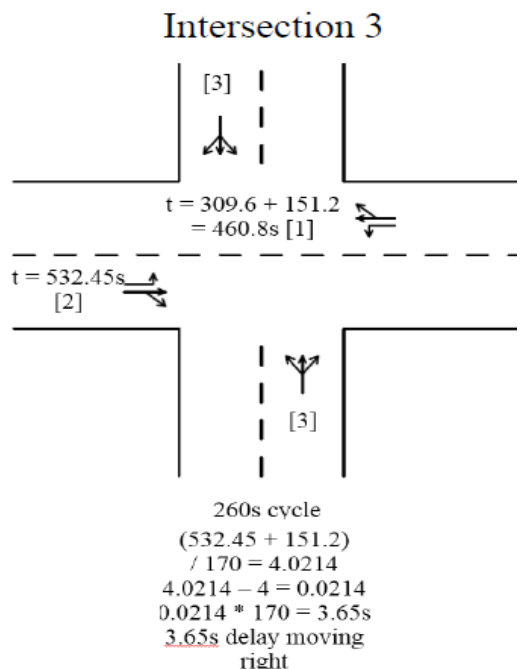

Fig. 7: Timings of Intersection 3.

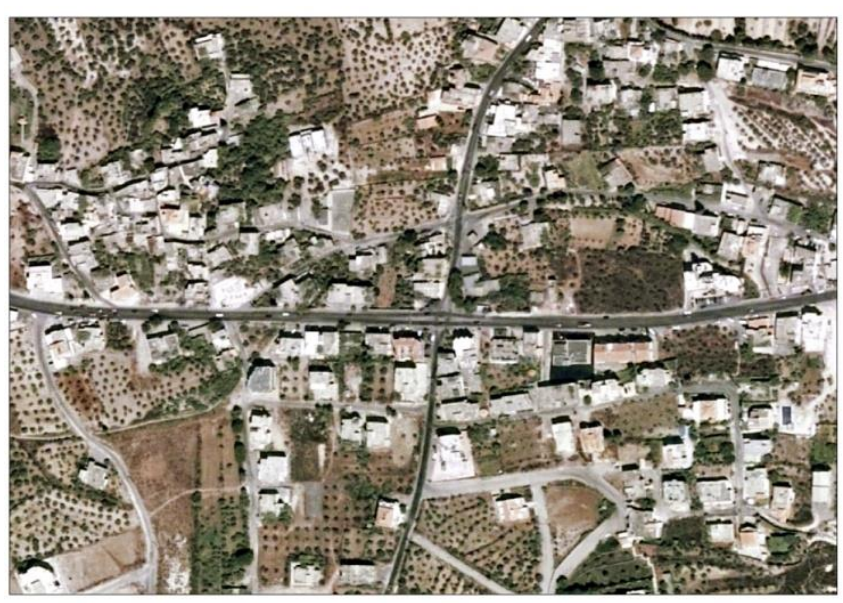

Fig. 8: Plan View of Intersection 3.

- Travel time from Intersection 1 to $2=(4.3 \mathrm{~km} * 3600 \mathrm{~km} / \mathrm{hr}) /(50 \mathrm{~km} / \mathrm{hr})=309.60 \mathrm{~s}$

- Travel time from Intersection 2 to $3=(2.1 \mathrm{~km} * 3600 \mathrm{~km} / \mathrm{hr}) /(50 \mathrm{~km} / \mathrm{hr})=151.20 \mathrm{~s}$ 
The above figures show specifically at what time each intersection starts. Starting with the first intersection and the first traffic light at $\mathrm{t}=0$ as per Figures 3 and 4 , the second phase will begin after 14.24 seconds and the third phase at 28.48 seconds. The distance between the first and second intersection is $4.3 \mathrm{~km}$, so at a $50 \mathrm{~km} / \mathrm{h}$ speed, the driver will reach the second intersection after 309.60 seconds, which is when the first phase at the second intersection turns green, as per Figures 5 and 6 . The second phase of the second intersection (which is the two left turns) turns green after 77.86 seconds, giving a grand total of 387.46 seconds from the first intersection. The third phase turns green after 5.92 seconds, giving a grand total of 393.38 seconds. The distance between the second intersection and the third intersection is $2.1 \mathrm{~km}$, so at 50 $\mathrm{km} / \mathrm{h}$ speed, the driver will reach the third intersection after 151.20 seconds giving a grand total of 460.80 seconds, as per Figures 7 and 8 . The second and third lights turn green after 74.17 seconds and 37.80 seconds, respectively.

At this stage the objective was to decide the sequence of the phases to reduce delays from every possible phase. The reason the first intersection is chosen like this will be explained later. For intersection 2, the different sequences will not cause that much of a difference since the left turn time is very small due to the low vehicle volume; however, for intersection 3, it makes a huge difference to choose N/S phase before the East going West phase. The reason being that, if a car coming from the first intersection decides to make a U-turn at the last intersection and the N/S is the second phase, the driver will be delayed 25 seconds by calculation; however if the East going West phase is the second phase, the driver will be delayed 3.65 seconds. Now, for the first intersection, the N/S phase was chosen to be the second because this causes the third phase to begin at 28.48 seconds. By calculations, the driver arrives at the traffic light at 29.60 seconds which means there are no delays.

Additional Lane per Direction - The parking lanes from the edges of the street were removed to increase the number of lanes (geometric change). These parking lanes are used by vehicles going into the commercial shops. As a result of this mitigation measure, parking provisions should be provided on the back streets.

\section{Conclusions and Recommendations}

After performing this study, there are many conclusions that may be drawn. First, the HCM method cannot be used in Lebanon due to the overpopulation of vehicles compared to the roads. This method requires such a low saturation that it cannot apply to most middle eastern countries, as such, no configuration will be acceptable. This leads to the next conclusion: Roadways in the Koura District in their current condition are not wide enough to handle these high densities of cars. Finally, a smart system for traffic management can have a very large impact on the lives of the inhabitants of the District.

\section{Acknowledgements}

The authors would like to express gratitude to Engineers Clay Faddoul and Ibrahim Jabr who were of great assistance in writing this paper and in data collection.

\section{References}

[1] Choueiri, Choueiri, \& Choueiri, "Analysis of Accident Patterns in Lebanon," 4th International Symposium on Highway Geometric Design, 2010.

[2] Lebanese Red Cross, Lebanese Red Cross Road Accidents Statistics for 2014, 2014. [Online]. Available: http://www.yasa.org/en/Sectiondet.aspx?id2=3238\&id=24.

[3] MoE 2000, Lebanon's Second National Communication to the UNFCCC, 2011.

[4] N. J. Garber, Lester A. Hoel, Traffic and Highway Engineering, 4th ed. University of Virginia, Virginia, pp. 327456.

[5] J. H. Banks, Introduction to Transportation Engineering, 2nd ed, San Francisco: McGraw-Hill, 2002.

[6] AASHTO, Roadside Design Guide. Washington, D.C: AASHTO 2002.

[7] K. Hamad, H. Abuhamda, "Estimating Base Saturation Flow Rate for Selected Signalized intersections in Doha, Qatar," Journal of Traffic and Logistics Engineering, vol. 3, no. 2, pp. 168-171, 2015. DOI: 10.12720/jtle.3.2.168171 ,

[8] U.S Department of Transportation, Federal Highway Administration, Manual on Uniform Traffic Control Devices, Washington, D.C.: Author, 2003. 